\title{
(Research Article) \\ Experimental Design for Optimal Removal of PAH from Crude Oil Waste using Aerobic Bioreactor
}

\author{
A. O. Ibeje ${ }^{1^{*}}$, H. I. Mbachu ${ }^{2}$, V. A. Wirnkor ${ }^{3}$ \\ ${ }^{1 *}$ Department of Civil Engineering, Imo State University, Owerri, NIGERIA \\ ${ }^{2}$ Department of Statistics, Imo State University, Owerri, NIGERIA \\ ${ }^{3}$ Department of Chemistry, Imo State University, Owerri, NIGERIA
}

\begin{abstract}
Crude oil waste contains recalcitrant pollutants and bioreactors offer a significant mechanism for the removal of these pollutants. The present work is concerned with the finding of the optimum conditions for removal of polycyclic aromatic hydrocarbons (PAHs) using bioreactors from crude oil sludge. The Box-Wilson method of experimental design was adopted to establish relationships between three operating variables (dosage of oxygen, $\mathrm{PAHs}$ concentration and $\mathrm{pH}$ ) that affect the treatment process. The experimental data were successfully fitted to a second-order polynomial mathematical model which was used to optimize the treatment process in discontinuous mode at laboratory scale. The most favorable operating condition for the treatment include; oxygen dosage $(0.4 \mathrm{~g})$, PAHs concentration $(20 \mathrm{mg} / \mathrm{L})$ and $\mathrm{pH}(6)$. On using the optimum conditions, a mathematical model simulating the treatment process was obtained. The results show that the bioreactor is very effective in removing PAH from crude oil sludge.
\end{abstract}

Keywords: PAH, Bioreactors, Experimental design, Optimization.

\section{Introduction}

The oil industry generates large quantities of oily and viscous residues, which are formed during production, transportation and refining [1]. These residues, called oily sludges, are composed of oil, water and solids [2]. This constitutes a multiphase system; making the residues highly recalcitrant and very difficult to reutilize. The marked stability of this multiphase system is due to the adsorption of oil into solid particles, producing a highly protective layer (as they tend to settle to the bottom of the tanks), and also due to the presence of surface-active compounds, which are responsible for the formation of emulsions. Additionally, the presence of organic polar fractions brings about charge repulsion, impairing the formation of a homogeneous phase [3]. From a chemical point of view, recalcitrance can be ascribed to the presence of aromatic hydrocarbons, polycyclic aromatic hydrocarbons (PAHs) and complex compounds with a very high molecular weight, such as asphaltenes [4].

It is estimated that approximately $1 \%$ of the total oil processed in Port Harcourt Refinery, Nigeria, is discharged as oily sludge, usually after being accumulated in storage tanks

"Corresponding Author: e-mail: engineeribeje@gmail.com,

Tel-+23439381505

ISSN 2320-7590

(C) 2019 Darshan Institute of Engg. \& Tech., All rights reserved for several years [5]. Incineration of this sludge is not recommended due to the high energy costs involved, the potential risk of air pollution and the persistence of PAHs. Similarly, the inadequate disposal of such a very toxic residue in landfills encourages the search for alternatives

The use of biological processes to treat waste or waste contaminated material is well-documented [6]. Bioprocess involves exploiting abilities of indigenous dosage or augmented microorganisms to metabolize organic substrates [7]. It can be accomplished in a land-based environment (landfarming, composting or biopiling) or in some cases bioremediation may be carried out in-situ by enhancing microbial degradation of contaminants in the subsurface of soil. In other cases, contaminated material may be treated in slurry bioreactors to degrade petroleum hydrocarbons. The process of landfarming has been implemented worldwide as a means of biological treatment and disposal of oily sludges [7]. The sludges are sprayed on land together with fertilizers and the soil is tilled to promote the activity of natural soil microbial population for the degradation of petroleum hydrocarbons. Although landfarming may be a low cost method if land is available, it requires very long treatment times due to lack of control on environmental factors such as seasonal variation in temperature, $\mathrm{pH}$, moisture, natural 
microbial activity, mixing and circulation limitations [8]. In climates with limited rainfall, the cost to maintain the proper moisture content in the soil could be prohibitive. Lack of uniformity causes high contaminant concentration/toxicity in localized pockets and inconsistent permeability of soil makes it difficult to apply treatment additives like nutrients and oxygen [9]. Care also needs to be taken to ensure that landfarms are isolated from watercourses. Most of the above limiting factors are eliminated in employing bioreactor technology. It eliminates the need to spray high concentrations of petroleum hydrocarbons on large areas of land.

Bioreactors allow the control of optimum process conditions required in the waste treatment. This allows for a higher quality final effluent in a shorter period of time, although costs are significantly higher. Despite their potential, the use of bioreactors is limited and most studies have focused on synthetic residues ([2]; [1]). However, promising results have been obtained for the treatment of an oily industrial sludge in a stirred bioreactor [10]. Similarly, Valero Refining Company has, for the first time, developed a process using a bioreactor on an industrial scale that was both economically viable and environmentally friendly [11].

This study is therefore focused on assessing the effects of various operational parameters, including $\mathrm{pH}, \mathrm{PAH}$ and oxygen concentration on the rate of the bioremediation of oily sludge using design of experiments (DOE) and to optimize the treatment processes in a laboratory scale mechanically stirred-tank bioreactors. The statistical models were validated by an additional set of experiments at the optimum conditions in line with the DOE results.

\section{Materials and Methods}

\subsection{The Reactor/Major Apparatus}

The experimental investigations were conducted in the elaborate laboratory bioreactor 2L-M with disk magnetic coupling as well as sliding bearings and maximum volume 2L.The bioreactor was included in an automatic control system (ACS). ACS was developed as three different blocks: in block dosimeters: the dosimeters for passing base, acid and foam slacked; and in block transformers- transformers for the basic measured values. The system, under control of a computer, allowed for regulation of parameters of the treatment process: $\mathrm{pH}$, $\mathrm{PAH}$ concentration and oxygen dosage.

\subsection{Mode of Data Collection}

The oily sludge was sampled from the Port Harcourt refinery in Rivers state, Nigeria. In order to achieve $\mathrm{pH}$ and alkalinity adjustment, the supernatant was neutralized with $\mathrm{NaOH}$ and $\mathrm{NaHCO}_{3}$. The ratio of COD: N: P was 300:5: 1 and this was kept during operation using $\mathrm{NH}_{4} \mathrm{Cl}$ and
$\mathrm{K}_{2} \mathrm{HPO}_{4}$. The micro-nutrient deficiency was added occasionally to correct growth conditions according to [12]. The initial oil and grease, paraffins and polyaromatics content of samples were determined before the experiment. Duplicate samples were withdrawn from the bioreactor and the organic phase is extracted by n-hexane in a separation funnel, passed through a layer of $\mathrm{Na}_{2} \mathrm{SO}_{4}$ in order to remove the humidity. Finally, the hydrocarbon consumption was evaluated by determining the oil and grease [13], paraffins $\left(\mathrm{nC}_{10}\right.$ to $\mathrm{nC}_{34}$, pristane, phytane) by Gas Chromatography using a flame ionization detector, and total polyaromatics by UV absorption in the wavelength range of $220-450 \mathrm{~nm}$ [11]. The Taguchi \& Humphrey method [14] was adopted to evaluate the Oxygen Uptake Rate (OUR) required by interrupting aeration and monitoring the decrease of oxygen concentration in the bioreactor. Specific Oxygen Uptake Rate (SOUR) was expressed as a function of the microbial biomass as measured by plate counts, assuming 1012 cells g-1 bacteria and 109 cells g-1 yeast [15].

The sludge was fed to the reactor with the help of a variable speed peristaltic pump. The reactor was be operated at various hydraulic retention times (HRTs) by varying the flow rate of influent wastewater $\left(Q_{\text {inf }}\right)$, thereby varying the loading rate (LR). At any given loading rate, the bioreactor was continuously operated until steady-state condition was achieved, when gas production rate in bioreactor became constant. Then effluent samples were collected and subjected to the analysis of the following parameters, i.e. influent and effluent COD, oil and grease, paraffins and total polyaromatics. Experiments were carried out as functions of oxygen dosage, $\mathrm{PAH}$ concentration, and $\mathrm{pH}$. To determine the effect of experimental factors on the bioreactor process, this method was also applied at different oxygen dosage, $\mathrm{PAH}$ concentration, and $\mathrm{pH}$ of the sludge suspension

\subsection{Experimental Design and Optimization}

A three-factor along with three levels (high, middle and low) in conjunction with response surface methodology (RSM) was used to maximize PAH removal. $\mathrm{pH}\left(\mathrm{X}_{1}\right)$, initial PAH concentration $\left(X_{2}\right)$ and oxygen dosage $\left(X_{3}\right)$ were used as independent factors in the DOE; whereas, the $\mathrm{PAH}$ removal (Y) was considered response variable. Thus, each factor was coded at three levels, from -1 to +1 , as shown in Table 1. A previous study [16] was used to determine and select the critical ranges of the factors. The model responses were formulated as a quadratic model shown as Equation (1) and estimate of the model parameters represented by coefficients of Equation (1) were evaluated by least-squares regression according to Montgomery [17].

$$
y=\beta_{0}+\sum_{i=1}^{k} \beta_{i} X_{i}+\sum_{i=1}^{k} \beta_{i i} X_{i}^{2}+\sum_{i=1}^{k-1} \sum_{j=2}^{k} \beta_{i j} X_{i} X_{j}+C
$$

where $\beta_{0}, \beta_{\mathrm{i}}, \beta_{\mathrm{ii}}$, and $\beta_{\mathrm{ij}}$ are the constant, linear, quadratic, and cross-factor interaction coefficients, respectively; $X_{i}$ and 
$\mathrm{X}_{\mathrm{j}}$ represent the coded independent variable and $\mathrm{i}$ or $\mathrm{j}$ is the number of independent variables; $Y_{i}$ is the predicted response; and $\mathrm{c}$ and $\mathrm{k}$ are the residual term and the number of factors, respectively.

Table 1: Coded levels of Factors for $3^{3}$ Central Composite Design (CCD)

\begin{tabular}{|c|c|c|c|}
\hline \multirow{2}{*}{ Factors } & \multicolumn{3}{|c|}{ Levels of Factor } \\
\cline { 2 - 4 } & Low & Middle & High \\
$(-1)$ & $(0)$ & $(+1)$ \\
\hline $\mathrm{pH}\left(\mathrm{X}_{1}\right)$ & 4 & 7 & 10 \\
\hline Concentration (mg/L) $\left(\mathrm{X}_{2}\right)$ & 50 & 100 & 150 \\
\hline Adsorbent dosage $(\mathrm{g} / \mathrm{L})$ & 0.5 & 1 & 1.5 \\
\hline$\left(\mathrm{X}_{3}\right)$ & & & \\
\hline
\end{tabular}

The Design-Expert 9.0.4.1 statistical software was employed for graphical and regression analysis to estimate the coefficients of the response functions. The significance of the independent variables, factor interactions, and model equations were examined by analysis of variance (ANOVA) at $95 \%$ confidence intervals (CI). Three-dimensional (3D) surfaces and two-dimensional (2D) contour plots were obtained while keeping another factor constant in the quadratic models. Additional experiments were carried out to validate the statistical models for maximum PAH removal. Optimal operating conditions were estimated using the numerical optimization method built in the software. Lastly, an additional experimental run was carried out to validate the predicted optimal conditions for the response function for the removal of PAH. The desirability multiple response method was used to combine the desirable ranges for the response to obtain a simultaneous objective function that represents the geometric mean of all transformed responses as given by Myers [18] in Equation (2).

$$
D=\left(d_{1} \times d_{2} \times \ldots d_{n}\right)^{1 / n}=\left(\prod_{i-1}^{n} d_{i}\right)^{1 / n}
$$

where $\mathrm{D}$, di, and $\mathrm{n}$ are the desirability objective function, response range, and the number of responses, respectively. If the analyzed response is found to be outside of the desirability range, the overall desirability function becomes zero. Therefore, for a simultaneous optimization, response is required to be assigned low value for optimization. In this case, the percent removal of PAH (d1) was maximized.

\section{Results and Discussion}

Table 2 shows the three-factor, three-level CCD with observed and predicted values for $\mathrm{PAH}$ removal by the developed quadratic models. Thus, to predict the response function for $\mathrm{PAH}$ removal, the second-order polynomial Equation (3) was developed:

$$
\begin{aligned}
& \mathrm{Q}=78.72+11.33 \mathrm{X}_{1}+17.15 \mathrm{X}_{2}-13.78 \mathrm{X}_{3} \\
& +7.05 \mathrm{X}_{1} \mathrm{X}_{2}-10.26 \mathrm{X}_{1} \mathrm{X}_{3}+9.96 \mathrm{X}_{2} \mathrm{X}_{3} \\
& -3.27 \mathrm{X}_{1}^{2}-8.86 \mathrm{X}_{2}^{2}-1.69 \mathrm{X}_{3}^{2}
\end{aligned}
$$

Equation (3) shows that among the factors considered in the experiment, the initial PAH concentration was the most influence on the amount of PAH removed. However, the model showed that to obtain good removal of the $\mathrm{PAH}, \mathrm{pH}$ $\left(\mathrm{X}_{1}\right)$ must be increased. The model also showed that the firstorder interaction between $\mathrm{pH}$ and the oxygen dosage $\left(\mathrm{X}_{1} \mathrm{X}_{3}\right)$ and the dual interaction of initial PAH concentration $\left(\mathrm{X}_{22}\right)$ were also important. In the model, certain factors such as the coefficient associated with the dual interaction of $\mathrm{pH}\left(\mathrm{X}_{12}\right)$ and oxygen dosage $\left(\mathrm{X}_{32}\right)$ had very low values and a test of significance model coefficients was used to verify that these terms were not influential.

Negative coefficients for the model components $X_{3}, X_{1} X_{3}$, $\mathrm{X}_{22}$, indicate unfavorable effects on the $\mathrm{PAH}$ removal. Whereas, positive coefficients for $\mathrm{X}_{1}, \mathrm{X}_{2}, \mathrm{X}_{1} \mathrm{X}_{2}, \mathrm{X}_{2} \mathrm{X}_{3}$, indicate favorable effects on the PAH removal. The model showed that when the PAH concentration $\left(\mathrm{X}_{2}\right)$ and $\mathrm{pH}\left(\mathrm{X}_{1}\right)$ were increased, the amount removed $(\mathrm{Y})$ increased. The oxygen dosage $\left(\mathrm{X}_{3}\right)$ had a negative effect on the $\mathrm{PAH}$ removal $(\mathrm{Y})$.

However, the positive effect on the amount of $\mathrm{PAH}$ removed ( $\mathrm{Y}$ ) by the interaction effects between $\mathrm{PAH}$ concentration and the oxygen dosage $\left(\mathrm{X}_{2} \mathrm{X}_{3}\right)$ implied that the oxygen dosage $\left(\mathrm{X}_{3}\right)$ have much less effect on the amount adsorbed $(\mathrm{Y})$ than the PAH concentration $\left(\mathrm{X}_{2}\right)$ under high concentration conditions. This is shown in Figure 1(a). As shown in Figure 1b, the effect of negative interaction between the $\mathrm{pH}$ and the oxygen dosage $\left(\mathrm{X}_{1} \mathrm{X}_{3}\right)$ means that $\mathrm{pH}$ had much more positive effects on the amount of PAH removed (Y) than the oxygen dosage $\mathrm{X}_{3}$.

Likewise, double interaction effects of PAH concentration $\left(\mathrm{X}_{22}\right), \mathrm{pH}\left(\mathrm{X}_{12}\right)$ and oxygen dosage $\left(\mathrm{X}_{32}\right)$ have negative effects on the amount removed such that a decrease in any of these factors causes a decrease in the amount removed.

3.1. Analysis of Variance (ANOVA)

The ANOVA results for the coded quadratic model for the response are reported in Table 3. In terms of coded factors, the models can be described by the following Equation (4), after discarding the insignificant terms: 


$$
\begin{aligned}
& Q=78.72+11.33 X_{1}+17.15 X_{2}+13.78 X_{3} \\
& +7.05 X_{1} X_{2}-10.26 X_{1} X_{3} \\
& +9.96 X_{2} X_{3}-8.86 X_{2}^{2}
\end{aligned}
$$

\begin{tabular}{|c|c|c|c|c|c|c|c|}
\hline \multirow[t]{2}{*}{ Run } & \multicolumn{3}{|c|}{ Coded values } & \multicolumn{3}{|c|}{$\begin{array}{c}\text { Experimental } \\
\text { value }\end{array}$} & \multirow[t]{2}{*}{$\begin{array}{l}\text { response Y } \\
(\mathrm{mg} / \mathrm{g})\end{array}$} \\
\hline & $\mathrm{X} 1$ & $\mathrm{X} 2$ & X3 & $\mathrm{X} 1$ & $\mathrm{X} 2$ & X3 & \\
\hline 1 & -1 & 0 & 1 & 4 & 100 & 1.5 & 54.95 \\
\hline 2 & 0 & 0 & 0 & 7 & 100 & 1 & 80.24 \\
\hline 3 & 1 & 0 & 1 & 10 & 100 & 1.5 & 64.3 \\
\hline 4 & -1 & 1 & 0 & 4 & 150 & 1 & 72.47 \\
\hline 5 & 0 & 1 & 1 & 7 & 150 & 1.5 & 78.29 \\
\hline 6 & 1 & 0 & -1 & 10 & 100 & 0.5 & 113.07 \\
\hline 7 & 0 & -1 & 1 & 7 & 50 & 1.5 & 31.15 \\
\hline 8 & 0 & 0 & 0 & 7 & 100 & 1 & 81.33 \\
\hline 9 & 0 & 0 & 0 & 7 & 100 & 1 & 77.11 \\
\hline 10 & 0 & 0 & 0 & 7 & 100 & 1 & 75.75 \\
\hline 11 & 1 & -1 & 0 & 10 & 50 & 1 & 46.59 \\
\hline 12 & -1 & -1 & 0 & 4 & 50 & 1 & 45.23 \\
\hline 13 & 0 & 0 & 0 & 7 & 100 & 1 & 79.15 \\
\hline 14 & 1 & 1 & 0 & 10 & 150 & 1 & 102.04 \\
\hline 15 & -1 & 0 & -1 & 4 & 100 & 0.5 & 62.67 \\
\hline 16 & 0 & -1 & -1 & 7 & 50 & 0.5 & 77.93 \\
\hline 17 & 0 & 1 & -1 & 7 & 150 & 0.5 & 85.28 \\
\hline
\end{tabular}

Table 2: $3^{3}$ Factorial CCD with Observed and Predicted PAH removal $(\mathrm{Y})$

Fisher's (F) exact test and comparing probability (p) values greater than $\mathrm{F}$. The "Prob $>\mathrm{F}$ " less than 0.05 indicated that model was significant. Especially larger $\mathrm{F}$-value with the associated $\mathrm{P}$ value (smaller than 0.05 , confidence intervals) means that the experimental systems can be modelled effectively with less error ([19], [20], [21]). Consequently, the model F-value for PAH removal implied that the model was significant. The results of the analysis of variance are summarized in Table 3 . Table 3 shows that the interaction effects between the $\mathrm{pH}$ of the oily sludge and the $\mathrm{PAH}$ concentration (X1X2), between the $\mathrm{pH}$ and the oxygen dosage (X1X3), between the PAH concentration and the oxygen dosage (X2X3) and the dual interaction of the $\mathrm{PAH}$ concentration (X22) were statistically significant in the AO7 dye removal, with p-values of 0.0417, 0.0085, 0.0099 and 0.0149 , respectively. As against the dual interaction effects of $\mathrm{pH}$ (X12) and dual interaction of the oxygen dosage (X32) which were not statistically significant on the removal of PAH with p-values of 0.5590 and 0.2745 , respectively.

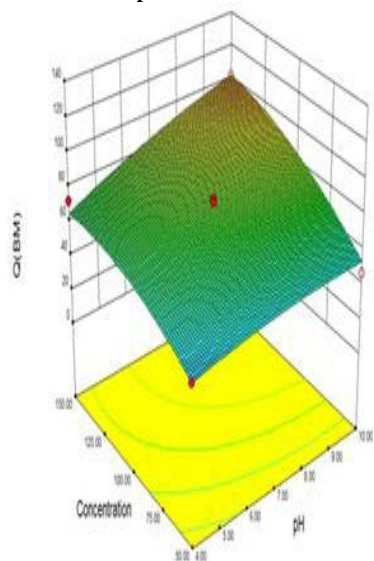

(a) Interaction effect of concentration of PAH and the $\mathrm{pH}\left(X_{1} X_{2}\right)$

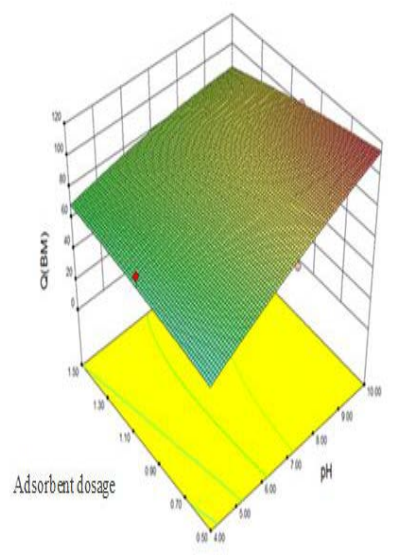

(b) Interaction effect of $\mathrm{pH}$ and the oxygen dosage

(X1X3)

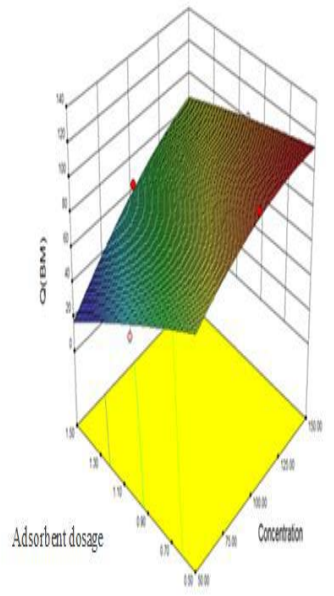

(c) Interaction effect of PAH concentration and the oxygen dosage(X2X3)

Figure 1: Surface Plots of Cross Factor Interaction

\subsection{Model Diagnosis}

The goodness of fit of the developed models was validated by the determination coefficient (R2) and the adjusted R2 that ensure an adequate variation of the quadratic model to the 
Table 3: ANOVA for Predicted Results for PAH removal $(\mathrm{Y})$

\begin{tabular}{|c|c|c|c|c|c|}
\hline Source & $\begin{array}{l}\text { Sum of } \\
\text { squares }\end{array}$ & Df & $\begin{array}{l}\text { Mean } \\
\text { square }\end{array}$ & $\begin{array}{c}\mathrm{F} \\
\text { value }\end{array}$ & $\begin{array}{c}\text { p-value } \\
\text { Prob > } \\
\text { F }\end{array}$ \\
\hline Model & 6329.148 & 9 & 703.239 & 21.891 & 0.0003 \\
\hline $\mathrm{X}_{1}-\mathrm{pH}$ & 1027.858 & 1 & 1027.858 & 31.996 & 0.0008 \\
\hline $\begin{array}{l}\mathrm{X}_{2^{-}} \\
\text {Concentration }\end{array}$ & 2352.294 & 1 & 2352.294 & 73.223 & $<0.0001$ \\
\hline $\begin{array}{l}\mathrm{X}_{3^{-}} \\
\text {absorbent } \\
\text { dosage }\end{array}$ & 1519.658 & 1 & 1519.658 & 47.305 & 0.0002 \\
\hline $\mathrm{X}_{1} \mathrm{X}_{2}$ & 198.951 & 1 & 198.951 & 6.193 & 0.0417 \\
\hline $\mathrm{X}_{1} \mathrm{X}_{3}$ & 421.276 & 1 & 421.276 & 12.117 & 0.0085 \\
\hline $\mathrm{X}_{2} \mathrm{X}_{3}$ & 395.811 & 1 & 395.811 & 12.321 & 0.0099 \\
\hline $\mathrm{X}_{1}^{2}$ & 45.140 & 1 & 45.140 & 1.405 & 0.2745 \\
\hline $\mathrm{X}_{2}{ }^{2}$ & 330.469 & 1 & 330.469 & 10.288 & 0.0149 \\
\hline $\mathrm{X}_{3}^{2}$ & 12.086 & 1 & 12.086 & 0.376 & 0.5590 \\
\hline Residual & 224.874 & 7 & 32.125 & & \\
\hline
\end{tabular}

experimental values. The values of R2 and adjusted R2 were found to be 0.9963 and 0.9928 for the PAH removal representing an adequate model's significance. The correlation between the observed and predicted values is shown in Figure 2(a) for PAH removal. As a result, minor discrepancies are represented by a straight line trend, which indicates a good agreement between observed and predicted values. Hence, the quadratic model for the prediction of PAH removal is satisfactory. These values for the model are close indicating a correspondence between the mathematical model and the experimental data. Figure 2(b) shows the residual values. It shows that the residue does not exceed the amount adsorbed, which is of the order of magnitude of the variety of experimental results due to handling. This residue is evenly distributed in space.

\subsection{Optimization of Operating Conditions}

The RSM was used to calculate the optimum conditions for

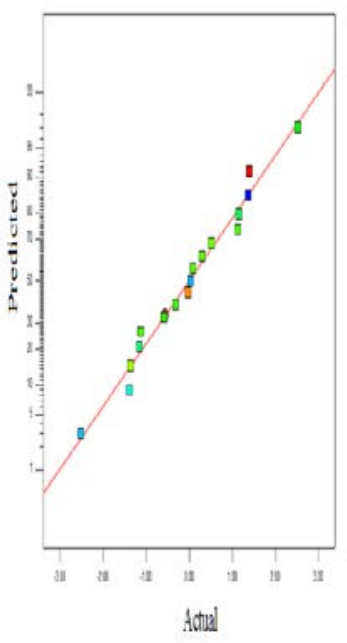

(a) Experimental and predicted response for $\mathrm{AO} 7$ dye removal

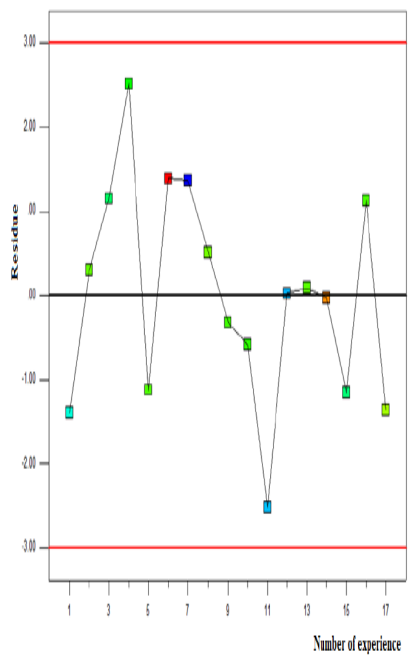

(b) Analysis of Residual for the Response
Figure 2: Tests of Model Assumptions

the three independent variables to get maximum percent PAHremoval. Equation (4) was defined as objective functions for PAH removal, and the independent factors in their range were used as model constraints. Thus, the following optimum conditions to reach a maximum $\mathrm{PAH}$ removal of $98.9 \%$ were found: dosage of oxygen $(0.4 \mathrm{~g})$, initial PAH concentration (20mg/L) and $\mathrm{pH}(6)$. The obtained optimal operating conditions were used in an additional run to validate the predicted values. A PAH removal of $97.8 \%$ was obtained experimentally, confirming the reliability of the model since the values are within the $95 \% \mathrm{CI}$.

\section{Conclusions}

In this study, experimental design was used to optimize the PAH removal from crude oil sludge using laboratory scale mechanically stirred-tank bioreactor and determine the effects of the operational factors $(\mathrm{pH}$, initial PAH concentration and oxygen dosage) on the removal of $\mathrm{PAH}$. The interaction effects of $\mathrm{pH}$, PAH concentration and oxygen dosage had a significant effect on PAH removal. To achieve maximum PAH removal, optimum conditions were found for each variable as dosage of oxygen $(0.4 \mathrm{~g})$, initial $\mathrm{PAH}$ concentration $(20 \mathrm{mg} / \mathrm{L})$ and $\mathrm{pH}(6)$. The results obtained in this study show that the laboratory scale mechanically stirredtank bioreactor is effective for the removal of PAHs from crude oil sludge. The developed mathematical model provides a comprehensive exploration of the cross-factor interactive effects of the independent variables on the responses. Future investigations should be conducted with a view to selectively separating other oily sludge contaminants, regenerating the exhausted biomass, recovering the removed $\mathrm{PAH}$ and designing to continuous oily sludge treatment systems. The result of the study produced a model that 
estimates the effect of $\mathrm{pH}$, initial $\mathrm{PAH}$ and oxygen concentration on the rate of the bioremediation of oily sludge and optimized the treatment processes in a laboratory scale mechanically stirred-tank bioreactor. The study would improve the performance of aerobic waste treatment plants through the use of physical models and the data from physical models to calibrate and verify mathematical models.

\section{Acknowledgement}

The authors wish to express their profound gratitude to the Tertiary Institution Trust Fund (TETFUND) for completely sponsoring this research through TETFUND Institution Based Research (IBR) project intervention of Fund Number: TETFUND/DRSS/UNIV/OWERRI/2015/RP/VOL.1/ 23.

\section{References}

1. Salameh, M. F. and Kabrick, R. M. "Treatment of Petroleum Oily Sludges in Liquid/Solid Contact Reactors - Results of Batch Testing”, in: Proceedings of the 46th Ind. Waste Conf., West Lafayette, Indiana, Purdue University, 2012.

2. Hahn, W. J. and Loehr, R. C. "Biological Treatment of Petroleum Oily Sludges", in proceedings of the Permian Basin Oil and Gas Recovery Conf., Texas, SPE - Soc. of Pet. Engineers, 2012.

3. Droste, R. LTheory and Practices of Water and Wastewater Treatment. John Wiley and Sons, . London, 2017.

4. Euiso, C. and Euisin, L. Temperature effects on biological nutrient removal system with weak municipal wastewater. Water Sci Technol Vol. 37, No.9, pp. 219-220, 2018.

5. SPDC Environmental Impact Assessment (EIA) of Egbema, Egbema West and Ugada Fields Integrated Oil and Gas Development Project. The Shell Petroleum Development Company Limited, Port Harcourt, Nigeria, 2010.

6. Atlas, R.M. and C.E. Cerniglia Bioremediation of petroleum pollutants: Diversity and environmental aspects of hydrocarbon biodegradation. BioScience, Vol. 45, pp. 332-338, 2015.

7. Ward, O.P. Bioprocessing. Milton Keynes, Open University Press, 2011.

8. Boopathy, R. Factors limiting bioremediation technologies. Bioresource Technology, Vol. 74, pp. 63-67, 2010.
9. Devinny, J.S. and Islander, R.L. Oxygen limitation in land treatment of concentrated waste. Hazardous Waste and Hazardous Materials, Vol. 6, pp. 421426, 2009.

10. Grega, M.D. and Evans, J.C. Waste Management. McGraw Hill, Inc., New York, USA, 2014.

11. Fitzgerald, M. E., Moirano, J. L., Morgan, H. and Cirillo, V. A. "Characterization of Gas Oil Stocks: An Integrated Analysis”, Appl. Spec., Vol.24, pp. 106-114, 2010.

12. Field, S. D. Advanced Biological Treatment and Separation of Hazardous Constituents from Petrochemical Sludges, J. of Hazard. Mat., Vol. 28, pp. 101-113, 2011.

13. American Standard Methods (ASTM) D1160. Standard Test Method for Distillation of Petroleum Products at Reduced Pressure, p.18, 2015.

14. Aiba, S., Humphrey, A. E. and Millis, N. F. "Instrumentation for Environmental Control". Biochemical Engineering, 2nd ed., New York \& London, Academic Press Inc., 2013.

15. Posten, C. H. and Cooney, C. L. Growth of Microorganisms, Biotechnology -Biological Fundaments, Vol. 1, 2nd ed., Weinheim, H. J. Rehm \& G. Reed, G. (eds.),VCH, 2016.

16. Ibeje, A. O. and Okoro, B.C. "Mathematical Modeling of Cassava Wastewater Treatment Using Anaerobic Baffled Reactor”. American Journal of Engineering and Science. Vol. 2, No. 5, pp. 128 134, 2013.

17. Montgomery, D. C. and Runger, G. C. Applied Statistics and Probability for Engineers. Third Edition. John Wiley \& Sons, Inc. London, 2012.

18. Myers, R.H., Montgomery, D.C., Vining, G.G., Borror, C.M. and Kowalski, S.M. Response Surface Methodology: A Retrospective and Literature Survey. Journal of Quality Technology, Vol.36, pp. 53-77, 2004.

19. Tukey J.W. Exploratory data analysis. Addison Wesley, Readind, MA, 1977.

20. Kutner M., Nachtsheim C., Neter J., and Li W. Applied Linear Statistical Models, McGrawHill/Irwin, Homewood, IL, 2004.

21. Box G. E. P. and Cox D. R. An analysis of transformations, J. R. Statist. Soc. B., Vol. 26, pp. 211-252, 1964.

\section{Biographical notes}

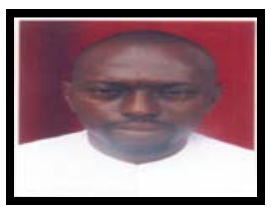

A. O. Ibeje has received his Ph.D. and M.Eng. from Federal University of Technology, Owerri, Nigeria, in Civil Engineering. He is a Senior Lecturer in the Department of Civil Engineering of Imo State University, Owerri, Nigeria. His research interest includes appropriate technologies for water and wastewater treatment. 